\title{
El sorprenent comportament d'algunes maquinetes de fer punxa al llapis
}

Josep Corominas

Escola Pia de Sitges

coromi6@pie.xtec.es

Quantes vegades no hem fet punxa al Ilapis? Algunes maquinetes són d'un material tal que se'n pot treure molt de profit a les classes de química.

\section{OBJ ECTIU}

Es tracta que observis els canvis químics que es produeixen i que els puguis relacionar amb fenòmens com la corrosió, la protecció contra la corrosió i altre processos electroquímics.

\section{Material}

- Maquineta de fer punxa als llapis, metàl-lica, de les marques Mor, Kum o Staedtler ${ }^{\circledR}$ que són de magnesi i tenen la fulla de tall d'acer.

- Vas de precipitats de $250 \mathrm{~mL}$

- Dissolució de sal en aigua

\section{Passos a realitzar}

1) Preparar una dissolució de sal en aigua, que sigui semblant a l'aigua de mar ( 3,5 g de sal en $100 \mathrm{~cm}^{3}$ d'aigua).

2) Submergir una maquineta en la dissolució. Es veu com es formen abundants bombolles d'hidrogen. Si es treu de la dissolució s'observa que s'ha produït corrosió del magnesi però no de la fulla d'acer

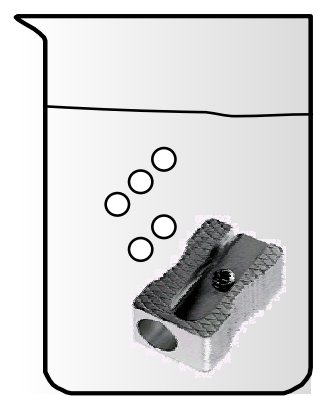

\section{Explicació}

El magnesi i l'acer de la fulla de tall formen una pila electroquímica, de manera que l'oxidació del magnesi evita que el ferro de l'acer es rovelli. Els valors dels potencials estàndard de reducció són:

$\begin{array}{ll}\mathrm{Mg}^{2+}(\mathrm{aq})+2 \mathrm{e}^{-} \longrightarrow \mathrm{Mg}(\mathrm{s}) & E^{o}=-2,37 \mathrm{~V} \\ \mathrm{Fe}^{2+}(\mathrm{aq})+2 \mathrm{e}^{-} \longrightarrow \mathrm{Fe}(\mathrm{s}) & E^{o}=-0,44 \mathrm{~V}\end{array}$

Aquest fenomen ens porta a intentar fer una pila amb material ben senzill: una maquineta i un llapis.

\section{PILA AMB MAQUINETA DE FER PUNXA} AL LLAPIS, I UN LLAPIS

\section{Material}

- La maquineta de fer punxa emprada en l'experiment anterior

- Dissolució de sal en aigua (la que s'ha fet servir abans)

- Llapis al qual se li ha fet punxa pels dos extrems.

- Cables elèctrics

- Un brunzidor (o un voltímetre amb escala $2 \mathrm{~V}$ )

\section{Procediment}

Es fa el muntatge indicat en el dibuix. Si es con-

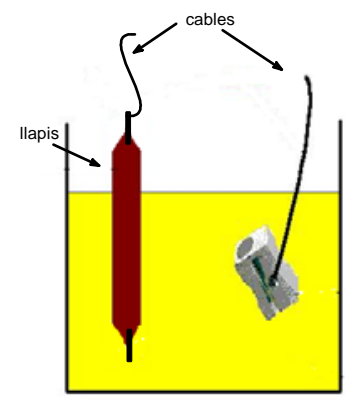


necten els cables al brunzidor, es posarà a fer soroll. Haurem fet una pila amb materials ben casolans.

\section{A ON ENS PORTA AQUESTA SÈRIE D'EXPERIMENTS?}

La manera més simple de protegir el ferro contra la corrosió és formant una barrera entre el metall i l'atmosfera. La barrera pot ser una capa de pintura, d'oli, de greix o d'un plàstic. Però, de vegades, el ferro es recobreix amb una fina capa d'un altre metall, per exemple el zinc. Aquest metall ha de tenir la propietat de ser més actiu que el ferro.

Quan dos metalls humits es posen en contacte, formen una pila electroquímica. El metall més actiu fa de pol negatiu (ànode) i el menys actiu de pol positiu (càtode). Aquest tipus de protecció s'anomena protecció anòdica i el metall que fa d'ànode és el metall de sacrifici.

La taula següent és l'anomenada sèrie galvànica, per a metalls submergits en aigua salada. Els metalls estan ordenats de més actius a menys actius. Els metalls més actius protegeixen els menys actius.

\begin{tabular}{|c|}
\hline $\begin{array}{c}\text { Sèrie galvànica per a metalls } \\
\text { en contacte amb aigua de mar } \\
\text { (de més a menys actiu) }\end{array}$ \\
magnesi \\
zinc \\
aliatges d'alumini \\
acer galvanitzat (acer recobert de zinc) \\
ferro de fosa \\
acer \\
plom \\
estany \\
coure \\
llautó (coure + zinc) \\
bronze (coure + estany) \\
plata \\
or \\
platí \\
--------------- \\
\end{tabular}

\section{Gestió dels residus}

Poden llençar-se a la pica

\section{BIBLIOGRAFIA}

The fragile life of a pencil sharpener. Chem 13News, Sep 1996.

Un sacapuntas y la oxidación de los metales. Revista electrònica El rincón de la ciencia, $\mathrm{n}^{\circ} 4$ : http://rinconciencia.go.to

Unitat "La química de l'acer". Projecte Salters de química per al batxillerat. Departament d'Ensenyament de la Generalitat de Catalunya. Centro de Desarrollo Curricular del Ministerio de Educación. Conselleria d'Educació i Cultura de la Generalitat Valenciana. 